\title{
Rare gastric submucosal mass: inflammatory myoblastic
}

\section{tumor}

\author{
Xiaoqian Lu, Ying Liu and Dianbo Cao* \\ Department of Radiology, The First Hospital of Jilin university, 71 XinMin Street, Chang Chun, China
}

\section{Case report}

A 51-year-old man was admitted with a 1-month history of intermittent fever up to $37.8^{\circ} \mathrm{C}$. The fever was not alleviated by antibiotics or antivirus drug. He had no history of serious illness, operation or hospitalization. Erythrocyte sedimentation rate and C-reactive protein were elevated at $120 \mathrm{~mm} / \mathrm{hr}$ and $106 \mathrm{mg} / \mathrm{L}$, respectively. Other blood tests were within normal limits. Endoscopy revealed a protruding mass situated on the lesser curvature of distal gastric body, near the angular incisure. Endoscopic ultrasound showed an oval hypoechoic mass, 33 $\mathrm{mm} \times 17 \mathrm{~mm}$ in size, arising from the muscularis propria layer (Figure 1). Abdominal computed tomography scan demonstrated a strongly enhancing mass in the posterior wall of gastric body, approximately $3.4 \mathrm{~cm}$ in the maximal diameter (Figure 2), which was associated with a submucosal lesion such as gastrointestinal stromal tumor, gastric glomus tumor and neuroendocrine tumor. The patient underwent local tumor excision. The cut surface of mass was grayish gelatinous texture (Figure 3). Microscopically, the tumor cells were characterized by proliferation of spindle-shaped atypical myofibroblastic cells and chronic inflammatory cells including plasma cells and lymphocytes (Figure 4). Inflammatory myoblastic tumor(IMT) was further diagnosed by immunohistochemistry, which showed positive staining for desmin and smooth muscle actin and was negative for CD117, CD34, and S-100. Lymph nodes tested negative for tumor. The preoperative fever disappeared and did not recur in the postoperative course.

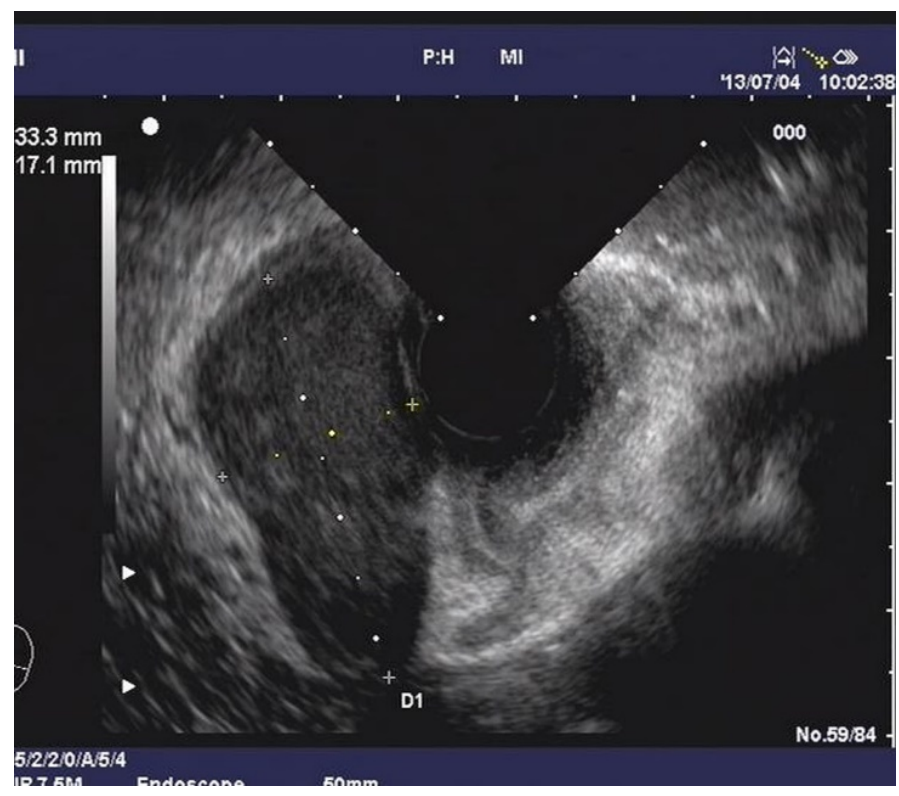

Figure 1. Endoscopic ultrasound.

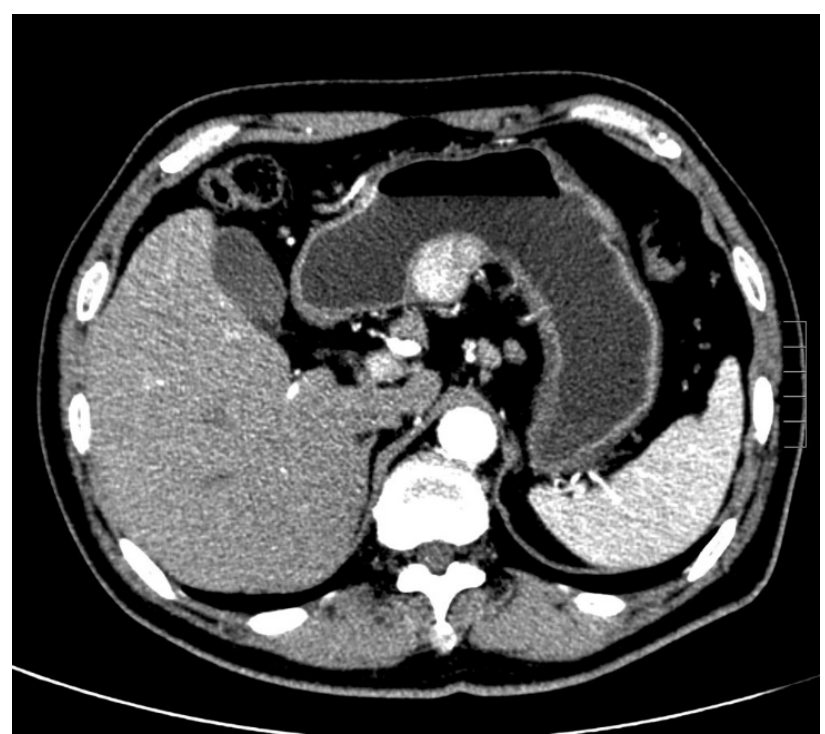

Figure 2. Abdominal computed tomography scan.

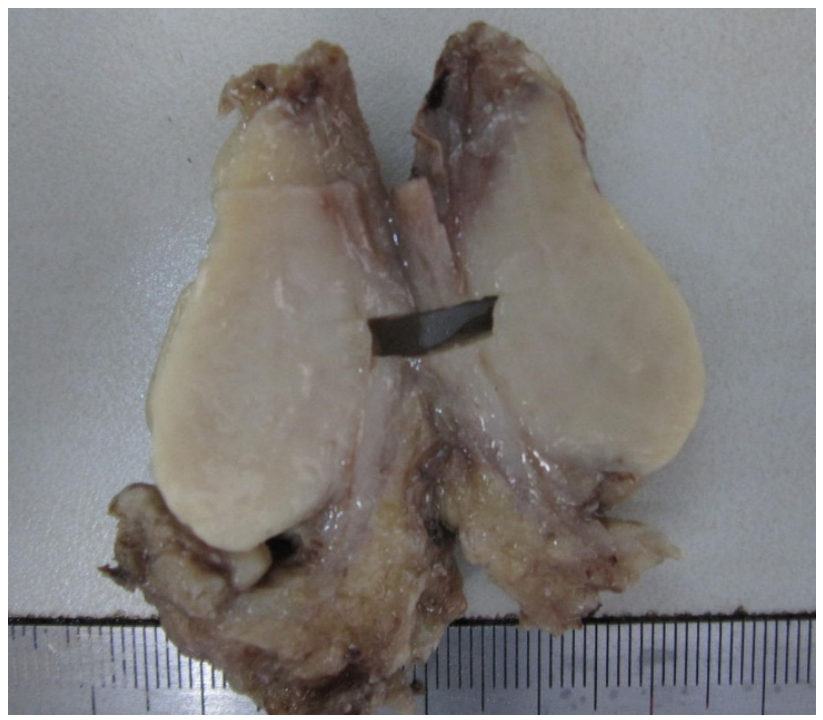

Figure 3. Cut surface of mass was grayish gelatinous texture.

*Correspondence to: Dianbo Cao, Department of Radiology, 71 XinMin Street, Chang Chun, China, Tel: 15804300125; E-mail: caotianbo@126.com

Received: April 06, 2018; Accepted: April 20, 2018; Published: April 24, 2018 


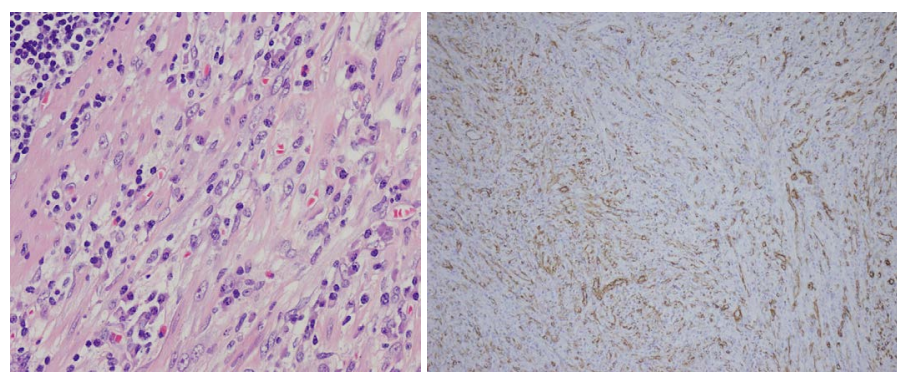

Figure 4. Microscopic proliferations

IMT has been defined as a histologically distinctive lesion of uncertain behavior and is composed of myofibrous spindle cells with inflammatory cell of infiltrate of plasma cells, lymphocytes and eosinophiles. The exact etiopathogenesis of IMT remains unclear, although various allergic, immunologic, and infectious mechanism have been postulated. IMT presents usually in children and young adults, and the lungs are the most commonly affected sites. In contrast to other
IMTs, gastric IMT in adults is very rare $[1,2]$. As in other pulmonary and extrapulmonary IMTs, gastric IMT is also accompanied with various clinical manifestations including fever, weight loss, normocytic to microcytic hypochromic anemia, thrombocytosis, elevated ESR, and hypergammaglobulinemia. Both clinical and radiological features are nonspecific, so the diagnosis of gastric IMT comes to light only after histopathological examination of the excision specimen. Due to the submucosal location of the tumor, endoscopic biopsies frequently reveal only normal or inflamed gastric mucosa, precluding pre-operative diagnosis. A complete surgical resection remains the only proven mode of cure and is proposed as the first line of treatment in all IMT cases.

\section{References}

1. Shi H, Wei L, Sun L, Guo A (2010) Primary gastric inflammatory myofibroblastic tumor: Aclinicopathologic and immunohistochemical study of 5 cases. Pathol Res Pract 206: 287-291. [Crossref]

2. Jain A, Kasana S, Ramrakhiani D, Sharma M (2012) Inflammatory myofibroblastic tumor of the stomach in an adult female--report of a rare case and review of the literature. Turk J Gastroenterol 23: 399-405. [Crossref]

Copyright: (C2018 Lu X. This is an open-access article distributed under the terms of the Creative Commons Attribution License, which permits unrestricted use, distribution, and reproduction in any medium, provided the original author and source are credited. 